Archiv at Louvain. Besides the present assemblage of papers, he has been responsible for Volumes 2,3 and 6 . Therefore, now may be the appropriate moment to offer him an expression of gratitude on behalf of those who are scholars of Husserl, both for shouldering a heavy burden, and no less for achieving such a high level of meticulous accuracy and comprehensiveness in the treatment of his most difficult material.

The collection now before us eomprises Husserl's lectures during the summer of 1925 on phenomenological psychology, together with some very important supplementary material, namely, his article in the Encyclopodia Britannica (fourteenth edition, 1929, and subsequent issues), and the course he gave in Amsterdam on the same subject. In addition, there are a number of appendixes and comments on the text. It is characteristic of the editor's care that whenever it has been desirable to modify Husserl's original titles, the fact is noted in special $<>$ brackets.

In general, these pages can be taken to cover what is essentially the whole of the master's thought up to that period on psychological and transcendental themes within the general conspectus of phenomenology.

Much of Husserl's labour consisted in an attempt (and in his view a triumphant one) to overcome the evils of psychologism, that is, the intrusion of psychological elements into what should be purely logical processes. He sees the methods of natural science and of psychology as quite distinct, except that both stand in need of some rationalization of the essential, if they are to become exact. Furthermore, it is clear that, on such a basis, phenomenological psychology and transcendental phenomenology together should improve the prospect that some day the ideal of Leibniz for an all-embracing science may materialize. In recent yoars, the rapid development of symbolic logic points to its possible conquest eventually of ethics and æsthetics. Even if this should prove to be the case, it would not invalidate Husserl's inclusion of metaphysics within his circle, nor yet of at least an element of teleology which seems to be inherent in some aspects of contemporary biological theory.

The importance of all this for present-day science lies perhaps in Husserl's profound grasp of the subjective. It may be that natural philosophy, in the widest sense, is moving outwards a little from its purely impersonal position into one in which mankind becomes more closely interwoven with the object of contemplation.

Husserl does not claim that adequate, apodeictic, fundamental knowledge follows of necessity from the use of the phenomenological method, but only that it can do so if the 'bracketing' or reduction-that is, suspension of judgment-and observation have been made with sufficient care. The divergent streams-historically speaking, transcendental for Descartes, psychological for Locke, Berkeley and Hume-are brought together again in phenomenology as the true successor of Platonic concepts and of all that is of the esse of Greek philosophy.

F. I. G. Rawlins

\section{THE SCIENCE OF PREHISTORY}

The Idea of Prehistory

(The New Thinker's Library.) By Dr. Glyn Daniel. Pp. viii $+171+8$ plates. (London : C. A. Watts and Co., Ltd., 1962.) $15 s$.

HE eight lectures here published were delivernd in 1956 as the second Josiah Mason Lectures in Archæology in the University of Birmingham. The material of prehistory is defined by the author as "the unwritten remains of the early past of man". It thus covers all those ages of human history which precede the literate cultures of the ancient world, as well as the non-literate cultures which continued to subsist alongside the peoples which possessed written records. The predominant role of archæology in producing the material of prehistory is well brought out, though archæology itself is correctly defined as covering a wider field extending right down to the recent past.

Prehistory is a newcomer in the learned world. The term itself was first used in 1851. Dr. Daniel records its gradual development, showing how the study drew on the older activities of the collectors and the dilettante, how it profited from the triumph of stratigraphical geology and how it was influenced by the evolutionary concepts of the nineteenth century. Finally, he sets out the most recent stage that lies within our own memory, when the study became firmly based on the scientific method, on the abundant material provided by archæology and on contacts with the natural sciences. Much of the material in the four lectures devoted to this development is well known; but the lucid and logical presentation gives it a new force and vigour.

The next three chapters discuss the relations, not always happy, of prehistory with other branches of study. Here the author is often treading on delicate ground. His account of the diffusionist theory and his unequivocal condemnation of the extravagances of the hyper-diffusionist heresy of the recent past is a model of balanced analysis and judgment. His condemnation of the racist uses of prehistory will find general assent. The discussion of the relations between prehistory and ethnographic and sociological studies is perhaps unduly pessimistic. The summary of the Russian approach (p. 120) was written before the availability in English of Mongait's survey, and does not represent the present position. On the other hand, his desire to see a closer integration of prehistory into the general historical perspective is most welcome. History in the narrower sense (that is, written history) has much to gain from a wider use of archæology; prehistory, which depends so largely on archæological material, should provide the methodological basis for the association.

The final chapter, "Prehistory and the Public", sits rather loosely on what has gone before. It shows clearly that public interest in early history and prehistory is no modern development and offers certain explanations of the popular interest in the subject. Dr. Daniel concludes that the "real justification of prehistory is not in origins or techniques or in perspective, but in pleasure; the pleasure of prehistory is in the recovery of the treasures of man's prehistoric past that have been dropped on the way and lost". $\quad$ C. A. RALEGH RADFORD

\section{PROGRESS AND PROPHECY IN SPACE}

\section{Advances in Space Science and Technology}

Vol. 4. Edited by Frederick I. Ordway III. Pp. xiv + 431. (New York and London: Academic Press, Inc., Publishers, 1962.) 100s.

$T$ HIS fourth volume follows the same pattern as its predecessors : six separate topics are reviewed in articles which average seventy pages each in length. In the first contribution, J. Mass and E. Vassy deal with the Doppler effect of artificial satellites. Starting from first principles, they show the manner in which the frequency of the received signal changes as a transmitting satellite passes by, and how this variation can be analysed for the purposes of orbital determination, navigation and scientific studies of the ionosphere. R. A. MacGowan is the author of the second contribution, a brilliant though inevitably somewhat speculative one on the possibilities of extra-terrestrial intelligence: he reviews the many theories of the origin of planetary systems (concluding 